\title{
Myocardial perfusion reserve of kidney transplant patients is well preserved
}

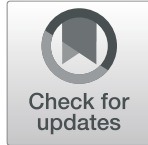

Johanna Päivärinta ${ }^{1,4^{*}} \mathbb{D}$, Kaj Metsärinne ${ }^{1}$, Eliisa Löyttyniemi ${ }^{3}$, Jarmo Teuho ${ }^{2,5}$, Tuula Tolvanen ${ }^{2,5}$, Juhani Knuuti ${ }^{2}$ and Niina Koivuviita'

\begin{abstract}
Background: Chronic kidney disease (CKD) is associated with endothelial dysfunction and increased cardiovascular mortality. Endothelial dysfunction can be studied measuring myocardial perfusion reserve (MPR). MPR is the ratio of stress and rest myocardial perfusion (MP) and reflects the capacity of vascular bed to increase perfusion and microvascular responsiveness. In this pilot study, our aim was to assess MPR of 19 patients with kidney transplant (CKD stages 2-3) and of ten healthy controls with quantitative $\left[{ }^{15} \mathrm{O}^{\mathrm{H}} \mathrm{H}_{2} \mathrm{O}\right.$ positron emission tomography (PET) method.

Results: Basal MP was statistically significantly higher at rest in the kidney transplant patients than in the healthy controls [1.3 (0.4) $\mathrm{ml} / \mathrm{min} / \mathrm{g}$ and $1.0(0.2) \mathrm{ml} / \mathrm{min} / \mathrm{g}$, respectively, $p=0.0015]$. After correction of basal MP by cardiac workload $\left[\mathrm{MP}_{\text {corr }}=\right.$ basal MP/individual rate pressure product $(\mathrm{RPP}) \times$ average RPP of the healthy controls], the difference between the groups disappeared $[0.9(0.2) \mathrm{ml} / \mathrm{min} / \mathrm{g}$ and $1.0(0.3) \mathrm{ml} / \mathrm{min} / \mathrm{g}$, respectively, $p=0.55)]$. There was no difference in stress MP between the kidney transplant patients and the healthy subjects $[3.8(1.0) \mathrm{ml} / \mathrm{min} / \mathrm{g}$ and $4.0(0.9) \mathrm{ml} / \mathrm{min} / \mathrm{g}$, respectively, $p=0.53$ ]. Although MPR was reduced, $\mathrm{MPR}_{\text {corr }}$ (stress MP/basal $\mathrm{MP}_{\text {corr }}$ ) did not differ between the kidney transplant patients and the healthy controls [4.1 (1.1) and 4.3 (1.6), respectively, $p=0.8$ ].
\end{abstract}

Conclusions: MP during stress is preserved in kidney transplant patients with CKD stage 2-3. The reduced MPR appears to be explained by increased resting MP. This is likely linked with increased cardiac workload due to sympathetic overactivation in kidney transplant patients.

Keywords: Renal transplant, Coronary perfusion, Positron emission tomography (PET), Kidney impairment

\section{Background}

The cardiovascular mortality risk is $10-20$ times higher in dialysis patients compared to the general population [1]. Although cardiovascular (CV) mortality seems to halt in patients with kidney transplant [2], their outcome still remains worse than that of the general population [3].

Endothelial dysfunction and oxidative stress are associated with rapidly developing atherosclerosis in advanced kidney disease [4]. The amount of nitric oxide (NO) and angiogenesis inhibitors also seem to increase in uremia inducing endothelial to mesenchymal transition in the myocardium. Consequently, fibrosis and capillary rarefaction occur $[5,6]$.

\footnotetext{
* Correspondence: johanna.paivarinta@fimnet.fi

${ }^{1}$ Department of Medicine, Division of Nephrology, Turku University Hospital, PL 52, Kiinamyllynkatu 4-8, 20521 Turku, Finland

${ }^{4}$ Department of Medicine, University of Turku, Turku, Finland

Full list of author information is available at the end of the article
}

Myocardial perfusion reserve (MPR), the ratio of hyperemic and basal blood perfusion, integrates the hemodynamic effects of epicardial stenosis, diffuse atherosclerosis, smooth muscle relaxation, and endothelial function [7]. CV mortality is known to increase with declining MPR [8]. In manifest epicardial coronary artery disease (CAD), stress myocardial perfusion (MP) begins to decrease after $40 \%$ of coronary stenosis [9]. Decreased MPR has been also documented in several preatherosclerotic states like hypertension [10] and dyslipidemia [11] without obstructive CAD. Furthermore, reduced MPR has been established in patients with mild to severe CKD [12-14], and it is associated with CV mortality also in patients with CKD $[15,16]$.

There are only a few Doppler echo-based studies of MPR in patients with kidney transplant $[17,18]$. Studies of MPR by positron emission tomography (PET) which has been considered the gold standard of quantitative 
tissue perfusion measurement are lacking in this patient group. Furthermore, there are no prospective studies comparing MPR measured while on dialysis treatment versus after transplantation. In cross-sectional Doppler-based studies, MPR has shown to be better in patients with kidney transplant than in patients in dialysis $[17,18]$.

In this pilot study, our aim was to assess MPR of kidney transplant patients without manifest atherosclerosis by means of $\left[{ }^{15} \mathrm{O}\right] \mathrm{H}_{2} \mathrm{O}$ PET and evaluate the technique for our future prospective study.

\section{Methods}

\section{Subjects}

Nineteen kidney transplant patients with estimated glomerular filtration rate $(e G F R)>30 \mathrm{ml} / \mathrm{min}$ and 10 healthy control subjects were included in the study. Patients were recruited from the nephrology outpatient clinic of Turku University Central Hospital during 2017-2018. Our aim was to study microvascular function. Thus, patients with CKD 4 (eGFR $<30 \mathrm{ml} / \mathrm{min})$ and/or with abdominal calcification score $(\mathrm{AAC})>8$ and/or with any clinical signs of atherosclerotic disease (CAD, cerebrovascular disease, peripheral artery disease) were excluded. None of the healthy controls had any history of heart or kidney disease or were on any medication.

\section{Study design}

Basal and stress MP and MPR were measured with $\left[{ }^{15} \mathrm{O}\right] \mathrm{H}_{2} \mathrm{O}$ PET. Laboratory samples were taken at the time of myocardial imaging. Pretransplantation AAC score was assessed from lateral lumbar radiography. Echocardiography was made as pretransplantation examination while the patients were in predialysis follow-up or in dialysis.

\section{Myocardial PET}

The imaging studies were carried out after a 10-h overnight fast. Caffeine and alcohol were prohibited for 1 day before assessment. Patients were instructed to take their medication as usual at study day except angiotensinconverting enzyme (ACE) inhibitors and angiotensin receptor blockers (ARB), which were discontinued 3 days before imaging due to renal imaging on the same day.

Venous catheter was placed in an antecubital vein for injection of oxygen-15-labeled water $\left[{ }^{15} \mathrm{O}\right] \mathrm{H}_{2} \mathrm{O}$ and adenosine. The subjects were positioned supine in the camera (Discovery 690 PET/CT scanner, GE Medical Systems, Waukesha, Wisconsin, USA). A low-dose helical CT scan with automatic dose modulation $(120 \mathrm{kVp}$, 10-80 mAs, noise index 30 , pitch of 1.375 , rotation time of $0.5 \mathrm{~s}$ ) was acquired during normal breathing before the resting PET scan to correct for photon scatter and attenuation. Electrocardiogram (ECG), heart rate (HR), and blood pressure were monitored continuously during the studies.

Rest and stress MP imaging with $\left[{ }^{15} \mathrm{O}\right] \mathrm{H}_{2} \mathrm{O}$ PET was performed as described earlier [19]. Oxygen-15-labeled water $(470 \mathrm{MBq})$ was injected (Radiowater Generator, Hidex Oy, Finland) at rest, and simultaneously, a PET perfusion scan was started. The dynamic acquisition scan of $4 \mathrm{~min} 40 \mathrm{~s}$ was performed with corresponding frame times of $(14 \times 5 \mathrm{~s}, 3 \times 10 \mathrm{~s}, 3 \times 20 \mathrm{~s}$, and $4 \times 30 \mathrm{~s})$. After a 10-min decay of the $\left[{ }^{15} \mathrm{O}\right] \mathrm{H}_{2} \mathrm{O}$ radioactivity, an identical $\left[{ }^{15} \mathrm{O}\right] \mathrm{H}_{2} \mathrm{O}$ PET $(470 \mathrm{MBq})$ sequence was performed during hyperemia. Adenosine was initiated $2 \mathrm{~min}$ before the stress scan for maximal vasodilatation. The mean radiation dose was $1 \mathrm{mSv}$ for the perfusion study.

The PET data were reconstructed using 3D ordered subset expectation maximization (vendor name: VUE Point HD) with point spread function modelling (vendor name: SharpIR) with a $128 \times 128$ matrix and FOV of $350 \mathrm{~mm}$ in size. The reconstructions were performed using 2 iterations, 24 subsets, and a Gaussian post-filter of $6.4 \mathrm{~mm}$. The PET images were reconstructed with all quantitative corrections applied to the reconstructed images, including attenuation, scatter, decay, and random corrections.

Global MP was analyzed with Carimas software [19, 20]. Arterial input function was extracted directly from the dynamic PET data. Single-tissue compartment model was used with correction for perfusable tissue fraction to generate parametric MP images $[19,20]$. MP was expressed in milliliters per minute per gram of perfusable tissue $(\mathrm{ml} / \mathrm{min} / \mathrm{g})$.

\section{Calculation formulas of MP}

MPR was calculated as the ratio of stress-to-rest MP. Because basal MP is related to the rate pressure product (RPP), an index of myocardial oxygen consumption, basal MP values were corrected for RPP (systolic blood pressure $\times \mathrm{HR}$ ) by the equation: basal $\mathrm{MP}_{\text {corr }}=$ basal $\mathrm{MP} /$ individual $\mathrm{RPP} \times$ average $\mathrm{RPP}$ of the healthy controls [21]. The average RPP of the healthy was used to make comparison of perfusion values between the patients and the healthy controls easier. Corrected MPR (MPR $\left.{ }_{\text {corr }}\right)$ was defined as the ratio of hyperemic MP divided by basal $\mathrm{MP}_{\text {corr }}$. Coronary vascular resistance (CVR) was calculated as mean arterial pressure (MAP) divided by global MP.

MAP after adenosine administration was calculated as mean of the 3- and 6-min MAP. Stress MP> $2.3 \mathrm{ml} /$ $\mathrm{min} / \mathrm{g}$, and MPR $>2.5$ were considered normal based on previous validation [19].

\section{Echocardiography}

Echocardiography was performed in $18 / 19$ patients as pretransplantation examination while the patients were in predialysis follow-up or in dialysis. The time between 
PET imaging and echocardiography varied from 1 year to 7 years. Left ventricular mass index (LVMI) and ejection fraction (EF) were measured. LVMI calculation was based on the Devereux equation [22] and normal values of LVMI on American Society of Echocardiography (ASE) convention [23]. According to ASE, reference range of LVMI for men is $49-115 \mathrm{~g} / \mathrm{m}^{2}$ and for female $43-95 \mathrm{~g} / \mathrm{m}^{2}$.

\section{AAC score}

The individual risk of atherosclerosis was evaluated before transplantation by AAC score in lateral lumbar radiography in $17 / 19$ patients [24]. The time between PET imaging and AAC score varied from 1 year to 7 years. We excluded patients with AAC score of more than $8 / 24$.

\section{Assessment of renal function}

The assessment of renal function was based on the eGFR equation from The Chronic Kidney Disease Epidemiology Collaboration (CKD-EPI) study [25]. CKD was referred according to the KDOQI definition. S-Crea and eGFR were measured within one month of PET imaging.

\section{Statistical analysis}

Comparisons between healthy controls and kidney transplant patients for continuous parameters were performed with Kruskal-Wallis test. Additional analyses were performed when males and females, diabetic and non-diabetic, were compared. In addition, correlation coefficients were calculated when associations were examined. All statistical tests were performed as two tailed, with a significance level set at 0.05 . The analyses were performed using SAS System, version 9.4 for Windows (SAS Institute Inc., Cary, NC, USA).

\section{Results}

\section{Study subjects}

The demographics of the study subjects are shown in the Table 1. Causes of CKD were as follows: 6 IgA nephropathies, 4 type I diabetic nephropathies, 1 lupus nephritis, 4 autosomal dominant polycystic kidney diseases, 2 medullary cystic kidney diseases, 1 FSGS, and 1 kidney disease without a specific diagnosis. One of the patients had a kidney-pancreas transplantation. Five patients were in hemodialysis (HD) before kidney transplantation and 14 patients in peritoneal dialysis (PD).

All the kidney transplant patients were on antihypertensive medication. Seven of 19 patients had either ACE inhibitor or ARB. Calcium channel blocker was used by 16 patients, beta blocker by 15 , and diuretic by 8 . There were 4 patients who had a combination of 3 antihypertensives and 3 who had a combination of 4 antihypertensives. Statins were used by 11 patients.
Table 1 Baseline characteristics

\begin{tabular}{|c|c|c|}
\hline & $\begin{array}{l}\text { Kidney transplant } \\
\text { patients }(N=19)\end{array}$ & $\begin{array}{l}\text { Controls } \\
(N=10)\end{array}$ \\
\hline Age (years) & $52(23-70)$ & $56(48-64)$ \\
\hline $\mathrm{BMI}(\mathrm{kg} / \mathrm{m} 2)$ & $28(5)$ & $26(4)$ \\
\hline Sex F/M (N) & $10 / 9$ & $7 / 3$ \\
\hline eGFR (ml/min) & $57(13)^{*}$ & $83(6)$ \\
\hline P-Crea $(\mu \mathrm{mol} / \mathrm{l})$ & $115(24)^{*}$ & $75(11)$ \\
\hline P-ProBNP (ng/l) & $199(191)^{*}$ & $119(121)$ \\
\hline $\mathrm{P}-\mathrm{TnT}(\mathrm{ng} / \mathrm{l})$ & $10(6)^{*}$ & $5(0)$ \\
\hline fP-chol (mmol/l) & $4.9(1.0)$ & \\
\hline $\mathrm{fP}-\mathrm{LDL}(\mathrm{mmol} / \mathrm{l})$ & $2.8(0.8)$ & \\
\hline $\mathrm{fP}-\mathrm{HDL}(\mathrm{mmol} / \mathrm{l})$ & $1.5(0.4)$ & \\
\hline $\mathrm{fP}-\mathrm{Tg}(\mathrm{mmol} / \mathrm{l})$ & $1.6(0.9)$ & \\
\hline $\mathrm{B}-\mathrm{Hb}(\mathrm{g} / \mathrm{l})$ & $140(11)$ & \\
\hline fP-gluk (mmol/l) & $6.0(1.7)$ & \\
\hline U-prot $(g / l)$ & $0.1(0.4)$ & \\
\hline Hypertensio arterialis (N) & 19 & 0 \\
\hline $\mathrm{DM} \mathrm{I} / \mathrm{II}(\mathrm{N})$ & $4 / 0$ & 0 \\
\hline Smoking (N) & 0 & 0 \\
\hline Time in dialysis (months) & $21(14)$ & 0 \\
\hline Age of kidney transplant (months) & $37(23)$ & \\
\hline
\end{tabular}

Values are mean (SD)

$B M l$ body mass index

${ }^{*} p<0.05$ controls versus kidney transplant patients

Four patients used a combination of tacrolimus, mycophenolate, and corticosteroid as immunosuppressive medication; seven patients used a combination of cyclosporine, mycophenolate, and corticosteroid; a combination of cyclosporine and mycophenolate was used by four patients and a combination of tacrolimus and mycophenolate by four patients.

AAC score was 0 in 13 patients, 3 in one, 5 in one, 6 in one, and 8 in one patient, and two of the patients did not have AAC score measured at all. Echocardiography was performed in 18/19 patients and there was an increased LVMI in 8/18 patients [mean LVMI 92 (26)]. All patients had normal EF [mean EF 66 (5)\%].

There was a statistically significant difference in eGFR and plasma creatinine between controls and transplant patients $(p<0.0001)$. P-ProBNP and P-Tnt were significantly higher in the kidney transplant group than in the controls $(p=0.013$ and $p=0.0009$, respectively).

\section{Hemodynamic measurements during imaging}

Hemodynamic measurements are shown in Table 2. Systolic and diastolic blood pressure, MAP, and HR at rest were higher in the transplant group than in the healthy controls $(p=0.0023, p=0.023, p=0.0044$, and $p=$ 0.0083 , respectively). Systolic blood pressure and MAP 
Table 2 Blood pressure and heart rate of the study subjects

\begin{tabular}{lll}
\hline & $\begin{array}{l}\text { Kidney transplant } \\
\text { patients }(N=19)\end{array}$ & $\begin{array}{l}\text { Controls } \\
(N=10)\end{array}$ \\
\hline Rest & $151(21)^{*}$ & $123(16)$ \\
BP systolic $(\mathrm{mmHg})$ & $82(16)^{*}$ & $70(9)$ \\
BP diastolic $(\mathrm{mmHg})$ & $106(16)^{*}$ & $88(11)$ \\
MAP (mmHg) & $66(12)^{*}$ & $55(4)$ \\
HR (beats/min) & & \\
Stress & $138(17)^{*}$ & $120(18)$ \\
BP systolic $(\mathrm{mmHg})$ & $71(8)$ & $65(9)$ \\
BP diastolic $(\mathrm{mmHg})$ & $93(9)^{*}$ & $84(11)$ \\
MAP (mmHg) & $89(13)$ & $86(14)$ \\
HR (beats/min) & &
\end{tabular}

Values are mean (SD)

$B P$ blood pressure, MAP mean arterial pressure, $H R$ heart rate

${ }^{*} p<0.05$ controls versus kidney transplant patients

at stress were higher in the kidney transplant patients than in the healthy controls $(p=0.03$ and 0.04 , respectively).

\section{Myocardial perfusion}

MP values are presented in Table 3. Basal MP as well as RPP were statistically significantly higher in the kidney transplant patients than in the control subjects $(p=$ 0.0044 and $p=0.0015$, respectively). The difference of basal MP between the groups disappeared after correction of basal MP by RPP $(p=0.31)$. There was no difference of statistical significance in stress MP or stress MPR between the groups $(p=0.53 ; p=0.15$, respectively). There were no differences in regional stress MP between the main coronary arteries. MPR in kidney transplant patients was lower than in controls, and the

Table 3 Myocardial flow values in all subjects

\begin{tabular}{lll}
\hline & $\begin{array}{l}\text { Kidney transplant } \\
\text { patients } \\
N=19\end{array}$ & $\begin{array}{l}\text { Controls } \\
N=10\end{array}$ \\
\hline Basal MP $(\mathrm{ml} / \mathrm{min} / \mathrm{g})$ & $1.3(0.4)^{*}$ & $1.0(0.2)$ \\
RPP & $10,053(2878)^{*}$ & 6723 \\
& & $(1112)$ \\
Basal MP corr & $(\mathrm{ml} / \mathrm{min} / \mathrm{g})$ & $1.0(0.3)$ \\
Stress MP $(\mathrm{ml} / \mathrm{min} / \mathrm{g})$ & $3.8(1.0)$ & $4.0(0.9)$ \\
MPR $_{\text {MPR }}$ & $3.0(0.9)^{*}$ & $4.2(1.0)$ \\
$\mathrm{CVR}_{\text {basal }}(\mathrm{mmHg} \mathrm{mL}$ & $\left.4.1 \mathrm{~min}^{-1} \mathrm{~g}^{-1}\right)$ & $83(1.1)$ \\
$\mathrm{CVR}_{\text {stress }}\left(\mathrm{mmHg} \mathrm{mL}^{-1} \mathrm{~min}^{-1}\right.$ & $27(9)$ & $93(21)$ \\
$\left.\mathrm{g}^{-1}\right)$ & & $22(8)$
\end{tabular}

Values are mean (SD)

$R P P$ rate pressure product, Basal MP $P_{\text {corr }}$ corrected basal MP, MP/individual $\mathrm{RPP} \times \mathrm{RPP}$ average of the healthy, MPR myocardial perfusion reserve, $M P R_{\text {corr }}$ corrected myocardial perfusion reserve, stress MP/basal $\mathrm{MP}_{\text {corr), }}$ CVR coronary vascular resistance

${ }^{*} p<0.05$ controls versus kidney transplant difference was statistically significant $(p=0.0029)$. However, after correction by RPP, the difference between the groups disappeared $(p=0.8)$.

\section{The effect of different parameters on myocardial perfusion}

There was no statistically significant difference in MP values between diabetics and non-diabetics (basal MP, $p=0.74$; stress MP, $p=0.19$; MPR, $p=0.31$ ) or between women and men (basal MP, $p=0.11$; stress MP, $p=0.66$; MPR, $p=0.14$ ). The previous dialysis type did not have any statistically significant effect on MP (basal MP, $p=$ 0.28 ; stress MP, $p=0.26$; MPR, $p=0.85$ ). There was no statistically significant correlation between $\mathrm{Hb}$, subject's age, age of the transplant, dialysis vintage, BMI or EF and basal or stress MP or MPR ( $p>0.05$ in all). There was a statistically significant correlation between LVMI and stress MP and $\mathrm{MPR}_{\text {corr }}(r=0.54, p=0.02 ; r=0.69$, $p=0.0017$, respectively).

Basal MP correlated with eGFR when 29 subjects of both groups were combined $(r=-0.43, p=0.019)$. However, the correlation disappeared after correction by cardiac workload $(r=-0.08, p=0.69)$. There was no correlation of statistical significance between the change of eGFR after transplantation (difference between eGFR at 1 year after transplantation and at the time of PET imaging) and MP values (basal MP, $p=0.42$; stress MP, $p=$ 0.63 ; MPR, $p=0.76$ ).

\section{Discussion}

This is the first study to report MP values of patients with kidney transplant based on $\left[{ }^{15} \mathrm{O}\right] \mathrm{H}_{2} \mathrm{O}$ PET which is considered the gold standard method of measuring tissue perfusion. The main finding of this study was that MP and CVR during stress are preserved in the kidney transplant patients with CKD stage 2-3. The reduced MPR appears to be explained by increased resting MP. This is likely linked with increased cardiac workload in transplant patients.

Basal MP was elevated $1.3(0.4) \mathrm{ml} / \mathrm{min} / \mathrm{g}$ in the kidney transplant patients compared to the value $1.0(0.2) \mathrm{ml} /$ $\mathrm{min} / \mathrm{g}$ of the healthy controls. Because the resting MP is related to myocardial work and metabolic demand, HR, and systolic blood pressure must be considered when comparing MP basal values within a study [21]. After RPP correction, the basal MP of the kidney transplant patients was equal with the MP of the healthy controls. Consequently, MPR was also equal in both groups after correction by cardiac workload.

Elevated RPP in patients with kidney transplant can be explained by sympathetic overactivation. Sympathetic overactivation has been established already in early stages of CKD [26]. Studies of autonomic nervous system in kidney transplant patients, based on HR variability and 
muscle sympathetic nerve activity, have shown that dysfunction of autonomic nervous system may improve after transplantation but it may also persist $[27,28]$.

Stress MP did not differ between the groups. It is very likely, that there was no obstructive CAD either in the patients or in the healthy controls, because there were no regional differences in stress MP between main coronary arteries. Furthermore, we used pretransplantation $\mathrm{AAC}$ score to estimate $\mathrm{CV}$ risk. Increasing $\mathrm{AAC}$ score, especially score values greater than $8-15$, has been associated with severely increased risk for $\mathrm{CV}$ events in dialysis patients [29-31]. AAC score 8 has been used as a cut-off value for high calcification in transplant patients $[32,33]$. Lewis et al. showed, that there is a continuous $7-8 \%$ increase in risk of $\mathrm{CV}$ events for each 1 point increase in AAC score without an exact cut-off point [33]. Based on these previous studies, AAC-score 0 in 13/17 patients and the highest AAC score 8/24 in our study should indicate mild to moderate $\mathrm{CV}$ risk.

\section{Myocardial perfusion in patients with CKD}

Like in our study, Charytan et al. did not find a statistically significant difference in stress MP and MPR by means of $\left[{ }^{13} \mathrm{~N}\right]$ ammonia PET between patients with stages 1-3 CKD and the healthy controls [34]. Similarly, a previous study of our group (Koivuviita et al.) showed by means of $\left[{ }^{15} \mathrm{O}\right] \mathrm{H}_{2} \mathrm{O}$ PET comparable stress MP between patients with stages 3-5 CKD and the control subjects [35]. Fukushima et al. had a finding pointing to the same direction in a $\left[{ }^{82} \mathrm{Rb}\right]$ PET study in patients with CKD stage 3 [13]. Furthermore, in an intracoronary guidewire study of Chade et al. with patients with CKD 3 without obstructive CAD, there was no difference in stress MP compared to the healthy controls [12].

Decreased stress MP has been demonstrated in patients with dialysis-dependent CKD [14, 17, 18, 36]. It is possible, that repeated dialysis sessions cause microvascular trauma decreasing stress MP. In our study, the average dialysis vintage was 21 months which was clearly shorter when compared with above-mentioned studies (48-95 months) [14, 17, 18, 36]. Accordingly, a correlation between dialysis vintage and MPR was shown in dialysis patients in two Doppler studies [17, 18].

\section{Myocardial perfusion in patients with kidney transplant}

In contrast to our study, decreased stress MP has been reported in patients with renal allograft with mild kidney impairment by means of Doppler [17, 18, 37]. Obstructive CAD was excluded on a clinical basis in those studies. The length of dialysis time before transplantation was shorter in our study (21 months) than in the Doppler-based studies (39-64 months) [17, 18, 37], which may have had impact on different results. In concordance with that assumption, there was a negative correlation between MPR and previous dialysis vintage of transplant patients in Doppler studies [17, 18]. We did not find any correlation between dialysis vintage and MPR, perhaps based on the short durance of dialysis treatment of our patients.

LVH has been associated with both decreased and increased stress MP $[38,39]$. In the above-mentioned Doppler studies, LVH was highly prevalent in transplant patients $[17,18]$. In our patients, there was increased LVMI in 8 of 18 patients in Doppler echo before transplantation. However, prevalence of increased LVMI at the time of PET scan was not known. There was a positive correlation between LVMI and stress MP in our study. In contrast to our result, LVMI correlated negatively with stress MP in Doppler studies $[17,18]$.

\section{Limitations}

There are some limitations in our study. Due to the long interval between echocardiography and PET imaging LVMI changes cannot be excluded [40]. However, there were no manifest heart failure episodes between the examinations probably speaking for heart failure with preserved EF.

In addition, the impact of antihypertensive medication on our results cannot be excluded, because only ATR blockers and ACE inhibitors were discontinued before the imaging. However, RAAS (renin-angiotensin-aldosterone-system) blockage has been most strongly associated with increased MPR [41, 42]. Finally, the sample size of our study was quite small.

\section{Conclusion}

In conclusion, this study showed the capability of $\left[{ }^{15} \mathrm{O}\right] \mathrm{H}_{2} \mathrm{O}$ PET in measuring MP of patients with kidney transplant. The difference in MPR between the healthy controls and the patients with kidney transplant can be explained by increased cardiac workload in transplant patients, which is probably associated with increased sympathetic activity. We are continuing our cardiac studies with prospective cohort of dialysis patients on kidney transplant waiting list.

\section{Acknowledgements}

Not applicable

Availability of data and materials

Please contact author for data requests.

Authors' contributions

JP took part in the conception and design of the study and in the interpretation of the data. She drafted the article. KM took part in conception and design of the study and provided intellectual content of critical importance to the work. He revised the article. EL took part in the analysis of the data and drafted statistical part of the manuscript. JT took part in drafting the imaging part of the study. TT took part in the design and work of imaging part of the study. JK took part in the conception and design of the study and provided intellectual content of critical importance to the work. He revised the article. NK took part in the conception and design of the study and in the interpretation of the data. She revised the article. She provided intellectual content of critical importance to the work. All authors read and approved the final manuscript. 


\section{Funding}

Grants were received from the Finska Läkaresällskapet (Helsinki, Finland), the Perklén Foundation (Helsinki, Finland), Varsinais-Suomi Regional Fund (Hertta and Veikko Valtonen Foundation), and The Finnish Society of Nephrology.

\section{Ethics approval and consent to participate}

All patients and controls gave a written informed consent. The study was approved by the Ethical Committee of the hospital district of Southwest Finland and it was conducted in accordance with the Declaration of Helsinki as revised in 1996.

\section{Consent for publication}

Not applicable

\section{Competing interests}

The authors declare that they have no competing interests.

\section{Author details}

'Department of Medicine, Division of Nephrology, Turku University Hospital, PL 52, Kiinamyllynkatu 4-8, 20521 Turku, Finland. ${ }^{2}$ Turku PET Centre, University of Turku, Turku, Finland. ${ }^{3}$ Department of Biostatistics, University of Turku, Turku, Finland. ${ }^{4}$ Department of Medicine, University of Turku, Turku, Finland. ${ }^{5}$ Department of Medical Physics, Division of Medical Imaging, Turku University Hospital, Turku, Finland.

\section{Received: 27 October 2019 Accepted: 3 February 2020}

\section{Published online: 10 February 2020}

\section{References}

1. Levey A, Beto J, Coronado B, et al. Controlling the epidemic of cardiovascular disease in chronic renal disease: What do we know? What do we need to learn? Where do we go from here? National Kidney Foundation Task Force on Cardiovascular Disease. Am J Kidney Dis. 1998. https://doi. org/10.1016/S0272-6386(98)70145-3.

2. Pilmore $\mathrm{H}$, Dent $\mathrm{H}$, Chang $\mathrm{S}$, et al. Reduction in cardiovascular death after kidney transplantation. Transplantation. 2010. https://doi.org/10.1097/TP. Ob013e3181caeead.

3. Bottomley MJ, Harden PN. Update on the long-term complications of renal transplantation. Br Med Bull. 2013. https://doi.org/10.1093/bmb/ldt012.

4. Stenvinkel $P$, Heimbürger $O$, Paultre $F$, et al. Strong association between malnutrition, inflammation, and atherosclerosis in chronic renal failure. Kidney Int. 1999. https://doi.org/10.1046/j.1523-1755.1999.00422.x.

5. Baylis C. Nitric oxide deficiency in chronic kidney disease. Am J Physiol Renal Physiol. 2008. https://doi.org/10.1152/ajprenal.00424.2007.

6. Charytan DM, Padera R, Helfand AM, et al. Increased concentration of circulating angiogenesis and nitric oxide inhibitors induces endothelial to mesenchymal transition and myocardial fibrosis in patients with chronic kidney disease. Int J Cardiol. 2014. https://doi.org/10.1016/j. ijcard.2014.06.062

7. Camici PG, d'Amati G, Rimoldi O. Coronary microvascular dysfunction: mechanisms and functional assessment. Nat Rev Cardiol. 2015. https://doi. org/10.1038/nrcardio.2014.160.

8. Taqueti VR, Hachamovitch R, Murthy VL, et al. Global coronary flow reserve is associated with adverse cardiovascular events independently of luminal angiographic severity and modifies the effect of early revascularization. Circulation. 2015. https://doi.org/10.1161/CIRCULATIONAHA.114.011939.

9. Uren NG, Melin JA, De Bruyne B, et al. Relation between myocardial blood flow and the severity of coronary-artery stenosis. N Engl J Med. 1994. https://doi.org/10.1056/NEJM199406233302503.

10. Laine $H$, Raitakari OT, Niinikoski $H$, et al. Early impairment of coronary flow reserve in young men with borderline hypertension. J Am Coll Cardiol. 1998. https://doi.org/10.1016/S0735-1097(98)00222-8.

11. Pitkanen OP, Raitakari OT, Niinikoski $\mathrm{H}$, et al. Coronary flow reserve is impaired in young men with familial hypercholesterolemia. J Am Coll Cardiol. 1996;28(7):1705.

12. Chade AR, Brosh D, Higano ST, et al. Mild renal insufficiency is associated with reduced coronary flow in patients with non-obstructive coronary artery disease. Kidney Int. 2006. https://doi.org/10.1038/sj.ki.5000031.

13. Fukushima K, Javadi MS, Higuchi T, et al. Impaired global myocardial flow dynamics despite normal left ventricular function and regional perfusion in chronic kidney disease: a quantitative analysis of clinical 82Rb PET/CT studies. J Nucl Med: official publication, Society of Nuclear Medicine.2012; doi: https://doi.org/10.2967/jnumed.111.099325

14. Tok D, Gullu H, Erdogan D, et al. Impaired coronary flow reserve in hemodialysis patients: a transthoracic Doppler echocardiographic study. Nephron Clin Pract. 2005. https://doi.org/10.1159/000087579.

15. Charytan DM, Skali H, Shah NR, et al. Coronary flow reserve is predictive of the risk of cardiovascular death regardless of chronic kidney disease stage. Kidney Int. 2018. https://doi.org/10.1016/j.kint.2017.07.025.

16. Shah NR, Charytan DM, Murthy VL, et al. Prognostic value of coronary flow reserve in patients with dialysis-dependent ESRD. J Am Soc Nephrol. 2016 https://doi.org/10.1681/ASN.2015030301.

17. Caliskan $Y$, Oflaz $H$, Demirturk $M$, et al. Coronary flow reserve dysfunction in hemodialysis and kidney transplant patients. Clin Transplant. 2008. https:// doi.org/10.1111/j.1399-0012.2008.00879.x.

18. Bozbas H, Pirat B, Demirtas $\mathrm{S}$, et al. Evaluation of coronary microvascular function in patients with end-stage renal disease, and renal allograft recipients. Atherosclerosis. 2008. https://doi.org/10.1016/j.atherosclerosis. 2008.04.043

19. Danad I, Uusitalo V, Kero T, et al. Quantitative assessment of myocardial perfusion in the detection of significant coronary artery disease cutoff values and diagnostic accuracy of quantitative [0-15] H2O PET imaging. Am Coll Cardiol. 2014. https://doi.org/10.1016/j.jacc.2014.05.069.

20. Harms HJ, Nesterov SV, Han C, et al. Comparison of clinical non-commercial tools for automated quantification of myocardial blood flow using oxygen15-labelled water PET/CT. Eur heart J Cardiovasc Imaging. 2014. https://doi. org/10.1093/ehjci/jet177.

21. Czernin J, Müller $P$, Chan $S$, et al. Influence of age and hemodynamics on myocardial blood flow and flow reserve. Circulation. 1993. https://doi.org/ 10.1161/01.CIR.88.1.62

22. Foppa M, Duncan BB, Rohde LEP. Echocardiography-based left ventricular mass estimation. How should we define hypertrophy? Cardiovasc Ultrasound. 2005. https://doi.org/10.1186/1476-7120-3-17.

23. Lang RM, Badano LP, Mor-Avi V, et al. Recommendations for cardiac chamber quantification by echocardiography in adults: an update from the American Society of Echocardiography and the European Association of Cardiovascular Imaging. Eur heart J Cardiovasc Imaging. 2015. https://doi. org/10.1093/ehjci/jev014.

24. Kauppila LI, Polak JF, Cupples LA, et al. New indices to classify location, severity and progression of calcific lesions in the abdominal aorta: a 25-year follow-up study. Atherosclerosis. 1997. https://doi.org/10.1016/S00219150(97)00106-8.

25. Levey AS, Stevens LA, Schmid $\mathrm{CH}$, et al. A new equation to estimate glomerular filtration rate. Ann Intern Med. 2009. https://doi.org/10.1059/ 0003-4819-150-9-200905050-00006

26. Grassi G, Quarti-Trevano F, Seravalle G, et al. Early sympathetic activation in the initial clinical stages of chronic renal failure. Hypertension. 2011. https:// doi.org/10.1161/HYPERTENSIONAHA.110.164780.

27. Hausberg M, Kosch M, Harmelink $P$, et al. Sympathetic nerve activity in endstage renal disease. Circulation. 2002. https://doi.org/10.1161/01.CIR. 0000034043.16664 .96

28. Yildiz A, Sever MS, Demirel, et al. Improvement of uremic autonomic dysfunction after renal transplantation: a heart rate variability study. Nephron. 1998;doi: https://doi.org/10.1159/000045126

29. Martino F, Di Loreto P, Giacomini D, et al. Abdominal aortic calcification is an independent predictor of cardiovascular events in peritoneal dialysis patients. Ther Apher Dial. 2013. https://doi.org/10.1111/j.1744-9987.2012.01084.x.

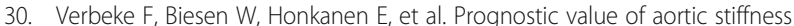
and calcification for cardiovascular events and mortality in dialysis patients: outcome of the calcification outcome in renal disease (CORD) study. Clin J Am Soc Nephrol. 2011. https://doi.org/10.2215/CJN.05120610.

31. Kwon HY, Lee OH, Kim MJ, et al. The association between mortality and abdominal aortic calcification and relation between its progression and serum calcium concentration in chronic hemodialysis patients. Kidney Res Clin Pract. 2014. https://doi.org/10.1016/j.krcp.2014.04.003.

32. Claes KJ, Heye S, Bammens B, et al. Aortic calcifications and arterial stiffness as predictors of cardiovascular events in incident renal transplant recipients. Transpl Int. 2013. https://doi.org/10.1111/tri.12151.

33. Lewis J, Wong G, Taverniti A, Vucak-Dzumhur M, Elder G. Association between aortic calcification, cardiovascular events, and mortality in kidney and pancreas-kidney transplant recipients. Am J Nephrol. 2019. https://doi. org/10.1159/000502328. 
34. Charytan DM, Shelbert HR, Di Carli MF. Coronary microvascular function in early chronic kidney disease. Circulation. Cardiovasc Imaging. 2010. https:/ doi.org/10.1161/CIRCIMAGING.110.957761.

35. Koivuviita $N$, Tertti $R$, Järvisalo $M$, et al. Increased basal myocardial perfusion in patients with chronic kidney disease without symptomatic coronary artery disease. Nephrol Dial Transplant. 2009. https://doi.org/10.1093/ndt/gfp175.

36. Nelson A, Dundon B, Worthley $S$, et al. End-stage renal failure is associated with impaired coronary microvascular function. Coron Artery Dis. 2019. https://doi.org/10.1097/MCA.0000000000000727.

37. Turiel $M$, Sitia S, Tomasoni $L$, et al. Subclinical impairment of coronary flow velocity reserve assessed by transthoracic echocardiography in young renal transplant recipients. Atherosclerosis. 2008. https://doi.org/10.1016/j. atherosclerosis.2008.09.036

38. Hamasaki S, Al Suwaidi J, Higano ST, et al. Attenuated coronary flow reserve and vascular remodeling in patients with hypertension and left ventricular hypertrophy. J Am Coll Cardiol. 2000;35(6):1654.

39. Kawecka-Jaszcz K, Czarnecka D, Olszanecka A, et al. Myocardial perfusion in hypertensive patients with normal coronary angiograms. J Hypertens. 2008; 26:1686-94.

40. Omrani H, Rai A, Daraei Z, et al. Study of echocardiographic changes after kidney transplantation in end-stage renal disease patients. Med Arch. 2017. https://doi.org/10.5455/medarh.2017.71.408-411.

41. Buus $N$, Bøttcher M, Jørgensen C, et al. Myocardial perfusion during longterm angiotensin-converting enzyme inhibition or $\beta$-blockade in patients with essential hypertension. Hypertension. 2004. https://doi.org/10.1161/01. HYP.0000141273.72768.b7.

42. Naya M, Tsukamoto T, Morita K, et al. Olmesartan, but not amlodipine, improves endothelium-dependent coronary dilation in hypertensive patients. J Am Coll Cardiol. 2007. https://doi.org/10.1016/j.jacc.2007.06.013.

\section{Publisher's Note}

Springer Nature remains neutral with regard to jurisdictional claims in published maps and institutional affiliations.

\section{Submit your manuscript to a SpringerOpen ${ }^{\circ}$ journal and benefit from:}

- Convenient online submission

- Rigorous peer review

- Open access: articles freely available online

- High visibility within the field

- Retaining the copyright to your article

Submit your next manuscript at $\boldsymbol{\nabla}$ springeropen.com 